\title{
Kinetics-Driven One-Dimensional Growth of Van der Waals Layered SnSe
}

Zhibin Liu ${ }^{1,2 *}$, Keda Ding ${ }^{2,3 \neq}$, Zhifu Liu ${ }^{1,2^{*}}$, Faqiang Zhang ${ }^{1}$, Huarong Zeng ${ }^{1}$, Kunqi

$$
X u^{1} \text {, Yiyang Sun }{ }^{3 *} \text {, Dong Wang }{ }^{1,2 *} \text {, Yongxiang } \mathrm{Li}^{4}
$$

${ }^{1}$ CAS Key Laboratory of Inorganic Functional Materials and Devices, Shanghai Institute of Ceramics, Chinese Academy of Sciences, Shanghai 201899, China

${ }^{2}$ Center of Materials Science and Optoelectronics Engineering, University of Chinese Academy of Sciences, Beijing 100049, China

${ }^{3}$ The key Lab of High-Performance Ceramics and Superfine Microstructure, Shanghai Institute of Ceramics, Chinese Academy of Sciences, Shanghai 201899, China

${ }^{4}$ School of Engineering, RMIT University, Melbourne, VIC. 3000, Australia

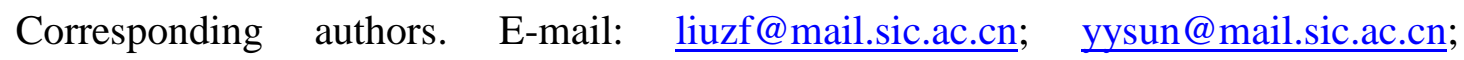
wangd@mail.sic.ac.cn

KEYWORDS: Quasi-1D vdW layered compounds; kinetics-driven; nanoribbon; inplane anisotropy 
Supporting Figures and Tables

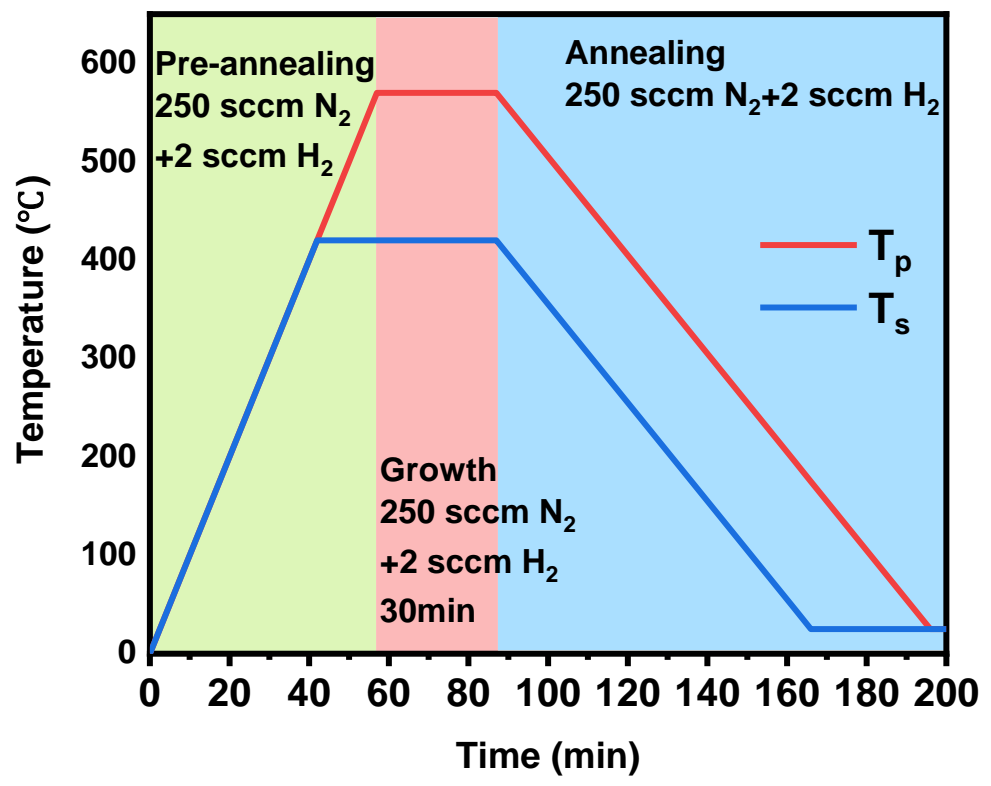

Figure S1 The temperature regime for the growth of SnSe. 
Table S1. Influence of evaporation temperature on sublimation of $10 \mathrm{mg} \mathrm{SnSe}$ powders

\begin{tabular}{ccc}
\hline $\begin{array}{c}\text { Evaporation } \\
\text { temperature (Tp) }\end{array}$ & $\begin{array}{c}\text { Growth } \\
\text { time (min) }\end{array}$ & $\begin{array}{c}\text { Sublimation } \\
\text { mass of SnSe } \\
\text { powders }\end{array}$ \\
\hline $560^{\circ} \mathrm{C}$ & 30 & $\sim 0.7 \mathrm{mg}$ \\
$570^{\circ} \mathrm{C}$ & 30 & $\sim 3.1 \mathrm{mg}$ \\
$585^{\circ} \mathrm{C}$ & 30 & $\sim 8.3 \mathrm{mg}$ \\
$600^{\circ} \mathrm{C}$ & 30 & $\sim 10 \mathrm{mg}$ \\
$600^{\circ} \mathrm{C}$ & 10 & $\sim 10 \mathrm{mg}$ \\
\hline
\end{tabular}



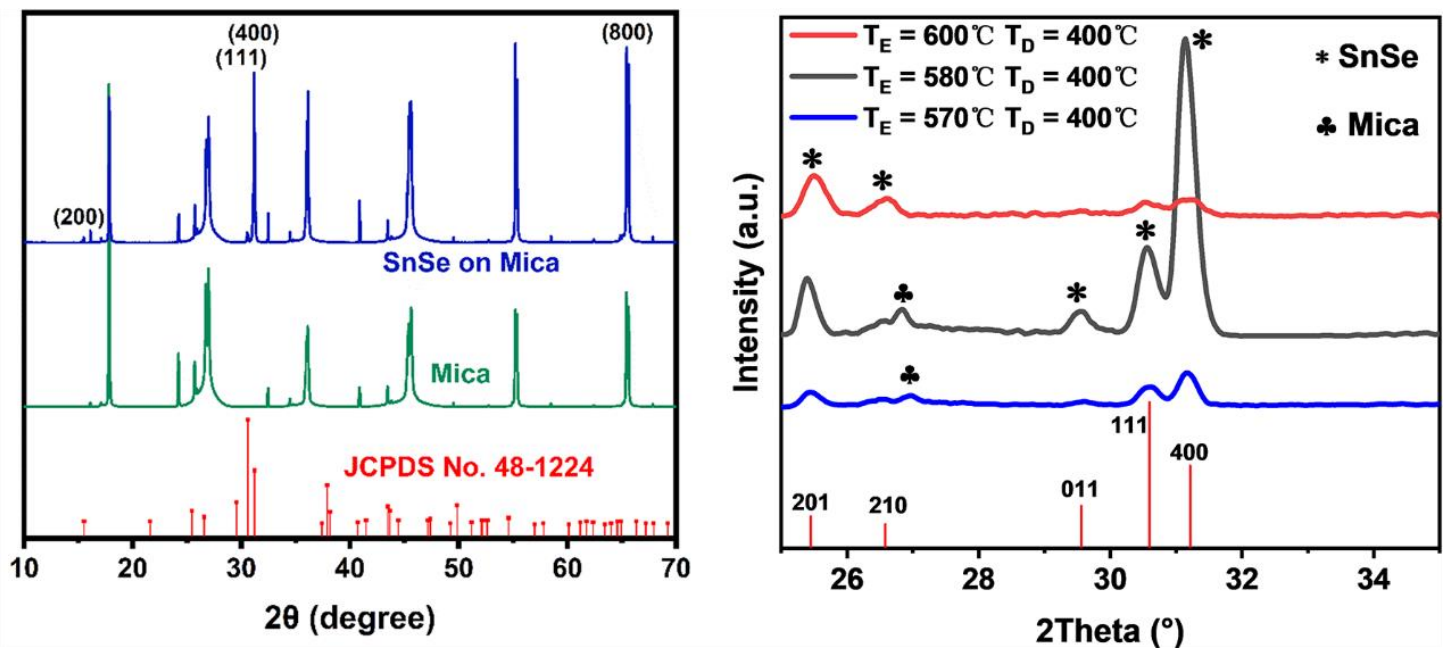

Figure S2 The XRD pattern of as-grown SnSe on mica substrate (a) and the XRD pattern of as-grown SnSe under different growth temperature. 

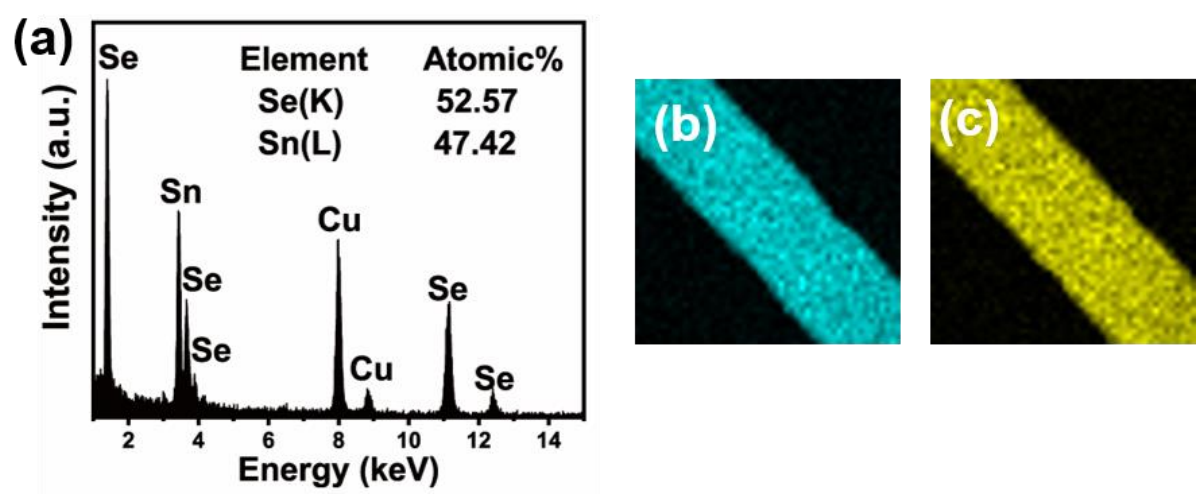

Figure S3 The EDS spectra (a) and element mapping of Sn (b) and Se (c) of SnSe nanoribbon. 

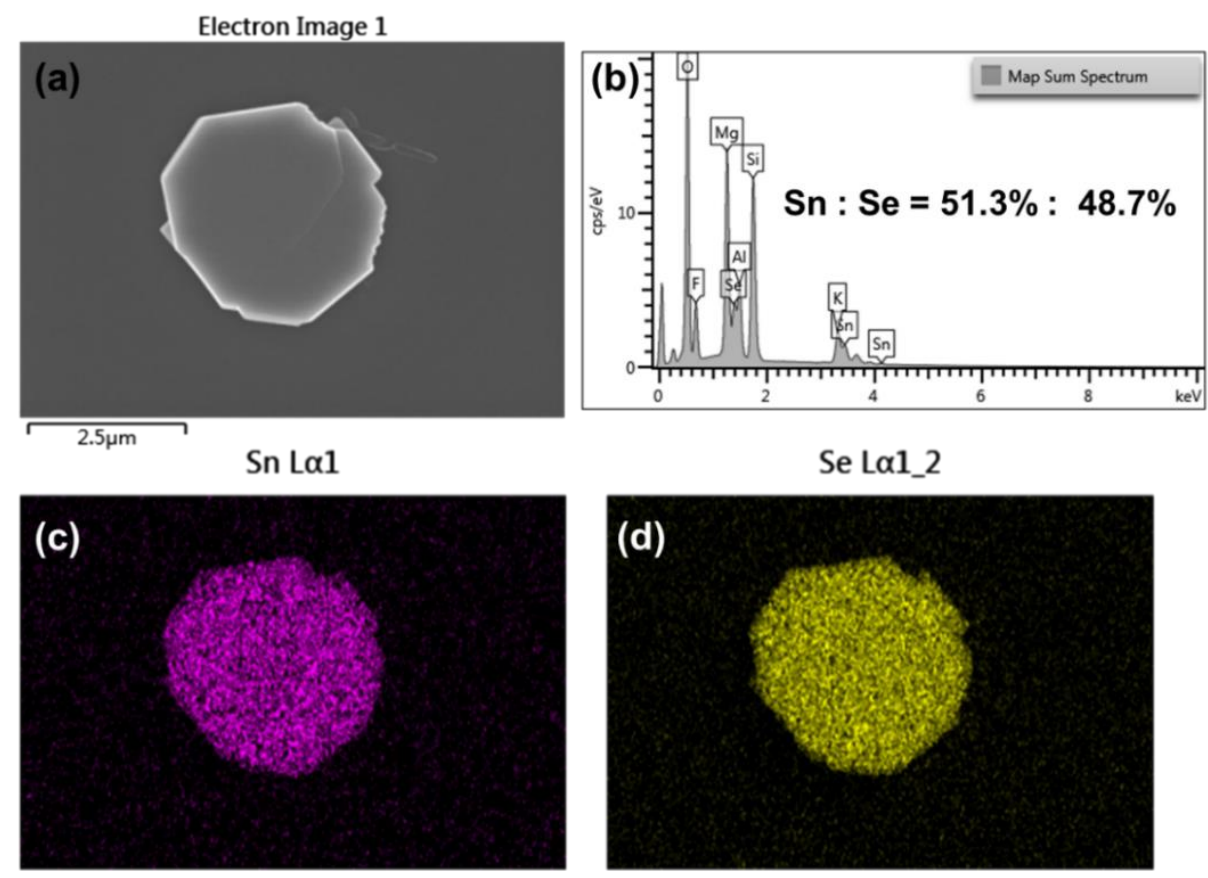

$2.5 \mu \mathrm{m}$

$2.5 \mu \mathrm{m}$
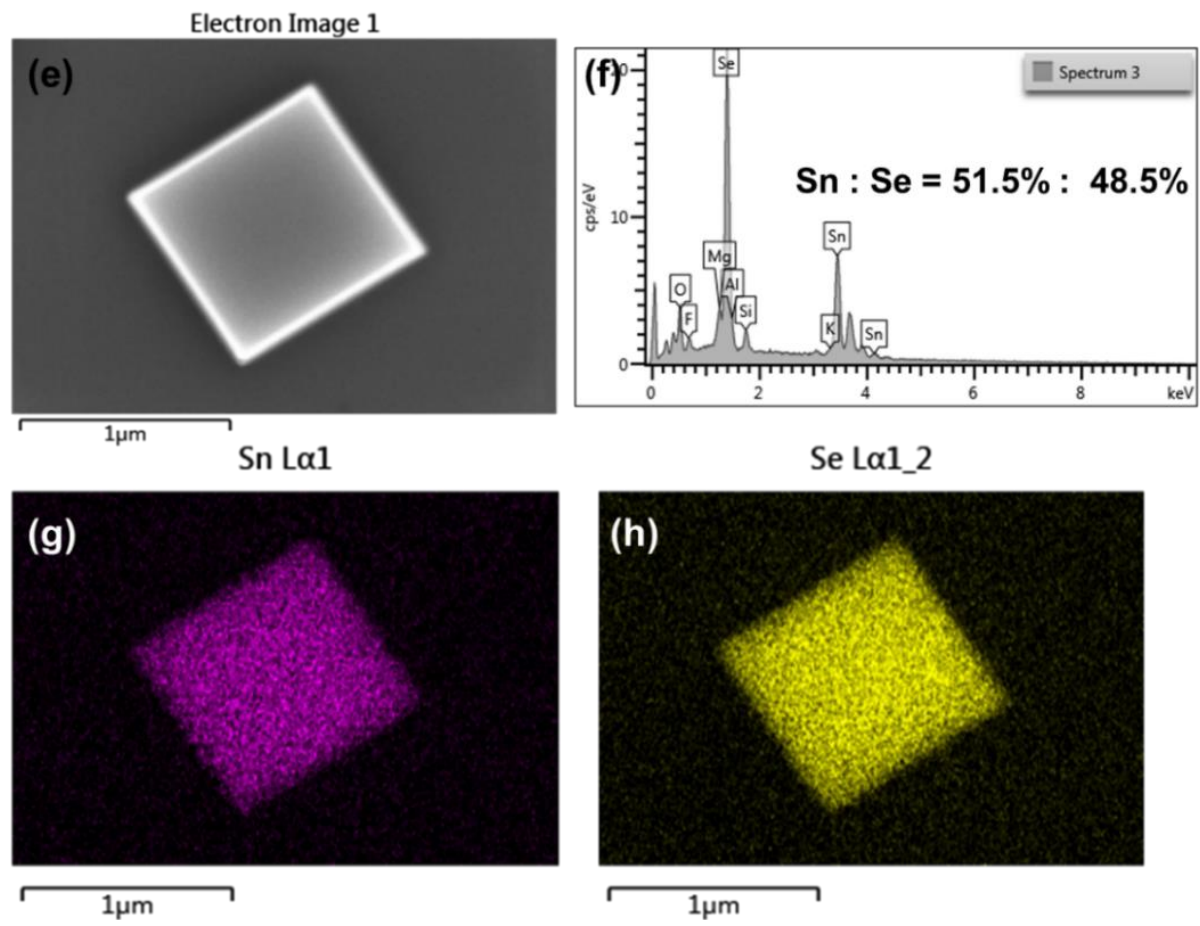

Figure S4 The SEM image, EDS spectra, elements Sn and Se mapping of SnSe rsNS (a-d) and SnSe NS (e-h). The signals of $\mathrm{K}, \mathrm{Mg}, \mathrm{Al}, \mathrm{Si}, \mathrm{O}$ and $\mathrm{F}$ come from the mica substrate $\left(\mathrm{KMg}_{3}\left(\mathrm{AlSi}_{3} \mathrm{O}_{10}\right) \mathrm{F}_{2}\right)$. 
hole
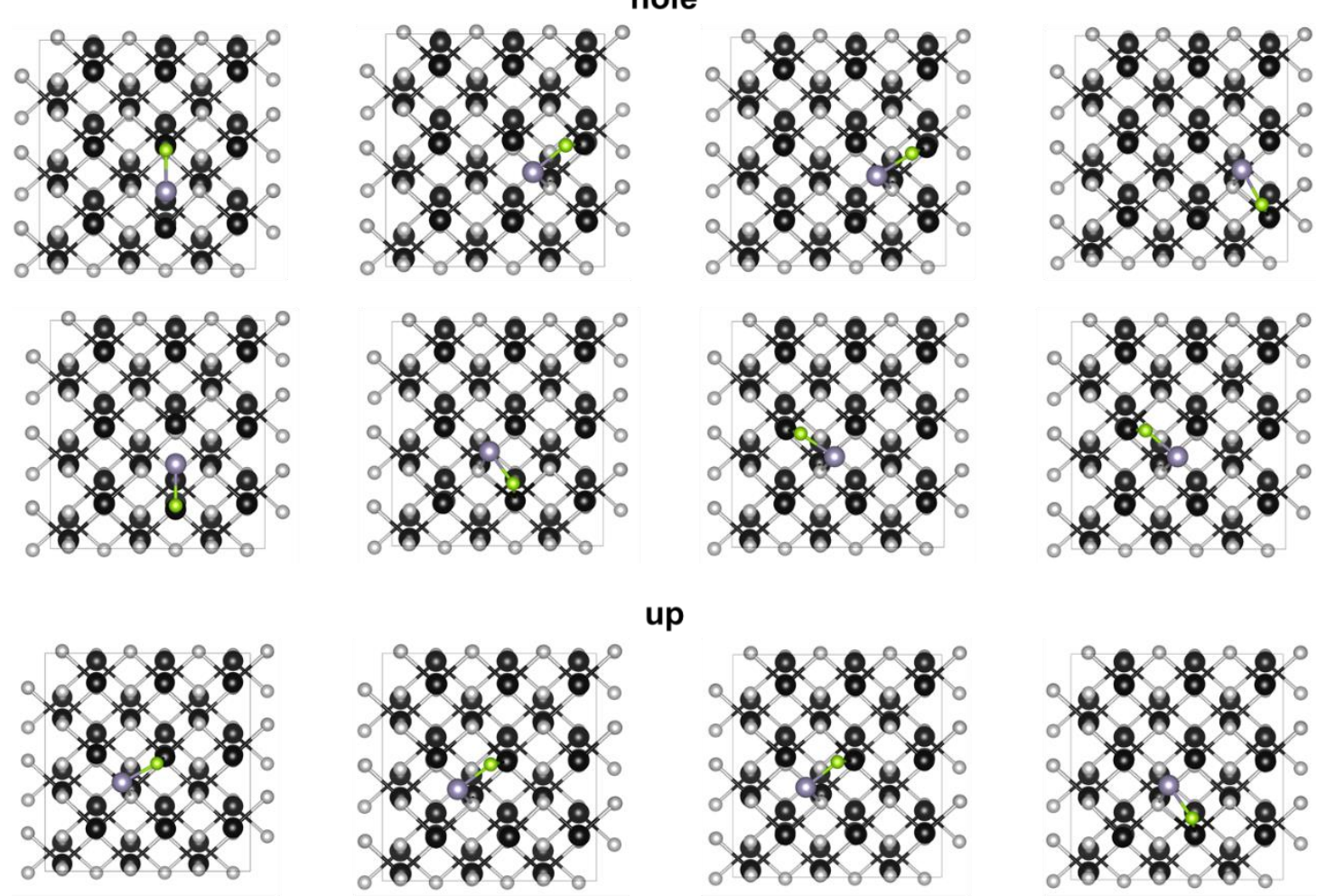

up
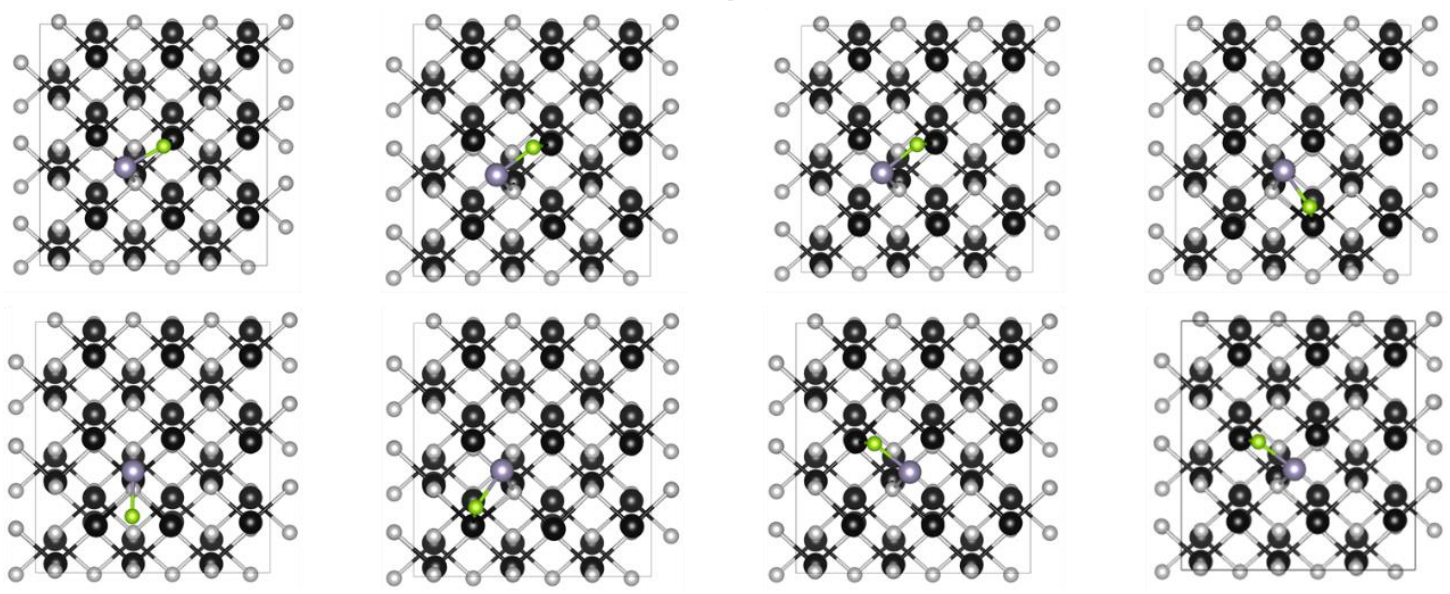

Figure S5 the configuration of SnSe molecular absorb on the (100) facet. 


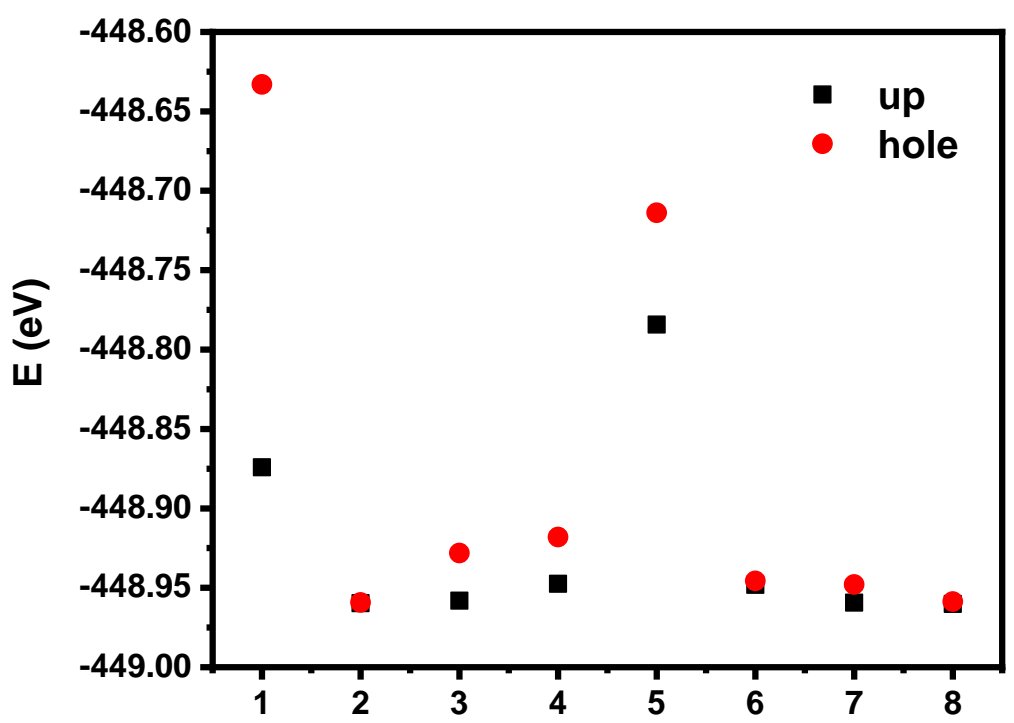

Figure S6 The energy of different SnSe molecular absorption location on the (100) facet. 